\title{
Effect of Pioglitazone on Expression of Interleukin- 17A, Toll-like receptor 2 , Inducible nitric oxide synthase 2 and Arginase 1 in Alzheimeric-model of rats Brain.
}

Mehrdad Jahanshahi (D mejahanshahi@yahoo.com )

University of Medical Sciences, Gorgan, Iran.

\section{Parisa Rahimi Chari}

Golestan University of Medical Sciences, Gorgan, Iran.

Ali Memarian

Golestan University of Medical Sciences, Gorgan, Iran.

Leila Elyasi

University of Medical Sciences, Gorgan, Iran.

\section{Research Article}

Keywords: Alzheimer's disease, Anti-inflammatory genes, Hippocampus, Neuroinflammation, Pioglitazone, Pre-inflammatory genes

Posted Date: February 1st, 2022

DOI: https://doi.org/10.21203/rs.3.rs-1285575/v1

License: (c) (i) This work is licensed under a Creative Commons Attribution 4.0 International License.

Read Full License 


\section{Abstract}

Introduction: Neuroinflammation is actively involved in neurological disorders such as Alzheimer's disease and it is one of the primary and permanent features of Alzheimer's disease. PPARy receptors are widely distributed in the brain and it is very important for learning. Agonists of this receptor such as pioglitazone can have beneficial effects in the treatment of Alzheimer's disease. In this study, the effect of pioglitazone (PPARy pathway agonist) on gene expression of Toll-like receptor 2 , interleukin A, inducible nitric oxide synthase 2, and arginase- 1 in the hippocampus Alzheimer's model of male rats was investigated.

Methods: In this study, 35 male Wistar rats were randomly divided into five groups of seven. The groups include control, Alzheimer's Sham group scopolamine (3 mg/ kg) +DMSO, and three groups receiving scopolamine+ pioglitazone with doses 5,10 , and $20 \mathrm{mg} / \mathrm{kg}$ for 12 days. All injections are intraperitoneal. In the end, hippocampal tissue was extracted to evaluate the expression of the desired genes by Real-time PCR and finally, SPSS software was used for statistical analysis of data.

Results: It was observed that the gene expression of Toll-like receptor 2, interleukin A and inducible nitric oxide synthase 2 in the Sco+DMSO group increased compared to the control group (except in the arginase-1 gene) and also the gene expression of these factors in the groups receiving pioglitazone decreased compared to the Sco+DMSO (except in the arginase-1 gene).

Conclusion: Pioglitazone can decrease the gene expression of Toll-like receptor 2, interleukin A and inducible nitric oxide synthase 2 and increase the gene expression of arginase- 1 in the rat brain. So pioglitazone is useful for the reduction of inflammation in the brain.

\section{Background}

The quality of life in Alzheimer's patients is low and often current therapy regimens are not sufficient to treat the disease. More than 70\% of dementia cases are Alzheimer's disease (AD), and in the 1990s, approximately 20.2 million cases of AD were reported. At the end of 2020, about 50 million people were reported to have $A D$ and by the end of 2050 , that number is expected to may reach 125 million [1].

Pathologically, $A D$ is marked by the presence of amyloid $\beta(A \beta)$ deposition and neurofibrillary tangles, the cholinergic system dysfunction, increase of oxidative stress, activation of microglia and, steady neuroinflammation [1]. Inflammatory markers detection in AD shows a potential role for neuroinflammation in the pathogenesis of this disease [2]. Neuroinflammation, the major checkpoint in AD's pathogenesis, is marked by an increase in proinflammatory cytokines, immune cells infiltration, and activated glial cells [3]. One of the main causes of neuroinflammation in AD is microglial activation [1] which is associated with the secretion of inflammatory cytokines and chemokines [4]. Microglia produces interleukin-17 (IL-17) protein [5] and this cell expresses toll-like receptors [6], inducible nitric oxide synthase (iNOS) [7]. Additionally, arginase 1 is another microglial activation marker that competes with iNOS for L-arginine and inhibits nitric oxide production [8]. 
Microglia is the first line of defense versus pathogens and other brain tissue injuries [9]. Microglia express types of toll-like receptors such as toll-like receptor 2 (TLR2) in the brain [6] which is a member of patternrecognition receptors in the innate immune system [10]. Toll-like receptors play a critical role in AD [6] and the gene of TLR2 is highly expressed in AD in the brain areas containing plaque formation [9]. This receptor has a dual role in $A D[9]$ including the clearance of $A \beta$ accumulation [11, 12], and induction of expression of pro-inflammatory molecules in response to $A \beta$ [11]. Indeed, stimulation of TLR2 by activating microglia induces $A \beta$ phagocytosis [9], and also, upregulating this receptor may be a treatment option in $A D$ by regulating the phagocytic activity of microglia [13].

IL-17, a pro-inflammatory cytokine [14], acts as a central regulator of the proinflammatory reaction in the brain $[5,15]$. IL-17 mRNA expresses in astrocytes and oligodendrocytes and IL-17 protein produces in microglia [5]. In AD, IL-17 is produced from microglia and its expression is increased in the hippocampus, cerebrospinal fluid, and serum after $A \beta-42$ peptide injection. But the exact mechanism of upregulation of $\mathrm{IL}-17$ in the brains of AD patients is still unknown [16].

iNOS express in central nervous system cells such as neurons and microglia $[7,17]$ and is involved in microglial activation [17]. In vivo and in vitro studies demonstrated that iNOS can induce neuronal apoptosis and also induce apoptosis in macrophages, astrocytes, and differentiated PC12 cells. Thus, neuronal damage in AD can reduce by inhibition of neuronal iNOS expression [18].

Hydrolysis of L-arginine to L-ornithine and urea is performed by arginase, which is a manganese metalloenzyme [19]. This enzyme is associated with central nervous system disorders including AD, multiple sclerosis, diabetic retinopathy, and retinopathy of prematurity. Two different genes encode two isoforms of arginase including arginase 1 and arginase 2 [20]. Brain-infiltrating macrophages on microglia express arginase 1 after central nervous system damage and these macrophages rely on arginase 1 expression to indicate a repair role to ameliorate injuries [21]. In an AD mouse model, IL-4 injection was induced arginase $1+$ microglia expression, which remarkably reduced $A \beta$ plaque accumulation under an IL-1 $\beta$ dependent neuroinflammation [22].

To treat hyperglycemia in type 2 diabetes is used pioglitazone which is an agonist of the peroxisome proliferator-activated receptor (PPAR) [23, 24]. PPAR is a ligand-activated transcription factor [25] which have three types including $a, \delta / \beta$, and $\gamma[26]$. These receptors have anti-inflammatory and antioxidant effects in brain damage or in neurodegenerative disorders including AD, ischemic stroke, and Parkinson's diseases [25]. PPARy express at the neuronal level in the rat hippocampus and cortex [27] and could be a new therapeutic approach for the treatment of $A D$ [28]. Additionally, these receptors with expression in microglia and astrocytes exert anti-inflammatory effects in the central nervous system [29]. The activation of these receptors in some cells, including macrophages, monocytes, and microglial cells reduces proinflammatory cytokine and iNOS expression [18]. It is reported that pioglitazone activates the PPAR- $y$ receptor and has a protective effect versus neuronal degeneration and cognitive deficits induced by binge alcohol with inhibition of pro-inflammatory cytokines in rats [30]. 
Pioglitazone, a thiazolidinedione derivative, inhibits Pam3CSK4-induced TLR2 expression in human monocytes and $\mathrm{db} / \mathrm{db}$ mice which indicates anti-inflammatory effects of this drug [31]. Also, the level of inflammatory bone destruction decreased with pioglitazone and this drug decrease the circulating and local expression of IL-17 in rats with adjuvant-induced arthritis [32].

Scopolamine, a non-selective muscarinic cholinergic antagonist, impairs memory and cognitive functions in human and animals [33], and this drug increase pro-inflammatory cytokines, and inflammation [33, 34]. Scopolamine may induce neuroinflammation by increasing the level of oxidative stress and proinflammatory cytokines in the hippocampus [35].

Although there are many studies on PPARy and pioglitazone, there are few studies on the effect of pioglitazone on anti-inflammatory and pro-inflammatory factors in the AD model of rats. In the current study, we used a scopolamine-induced model of $A D$ to show the treatment effect of pioglitazone on neuroinflammation and to provide a feasible theoretical basis and therapeutic target for AD treatment.

\section{Methods}

\section{Animals}

Adult male Wistar rats at 10 weeks of age were obtained from Pishro mehravaran azma pars (Babul, Iran), kept individually, and had access to free food and water. Rats acclimatized for 1 week in an animal room at $22 \pm 3{ }^{\circ} \mathrm{C}$ temperature with a $12 / 12$-h light-dark cycle. All experimental methods were performed in accordance with the National Institutes of Health Guide (NIH Publications No. 8023, revised 1978) for the Care and Use of Laboratory Animals. This study was approved by the Ethics Committee of Golestan University of Medical Sciences, Gorgan, Iran (Ethics number: ir.goums.rec.1399.346).

\section{Experimental design}

A total of 35 Wistar rats were randomly divided into 5 groups; each group included 7 rats, as follows:

Group 1: A control group that did not receive any drug.

Group 2 (Sco+DMSO group): A group that received scopolamine at a dose of $3 \mathrm{mg} / \mathrm{kg} / \mathrm{day}[36,37]$ for one day and DMSO injection for 12 consecutive days.

Group 3 (Sco+Pio $5 \mathrm{mg} / \mathrm{kg}$ group): A group that received scopolamine at a dose of $3 \mathrm{mg} / \mathrm{kg} /$ day for one day and was treated with pioglitazone $5 \mathrm{mg} / \mathrm{kg} /$ day for 12 consecutive days.

Group 4 (Sco+Pio $10 \mathrm{mg} / \mathrm{kg}$ group): A group that received scopolamine at a dose of $3 \mathrm{mg} / \mathrm{kg} / \mathrm{day}$ for one day and was treated with pioglitazone $10 \mathrm{mg} / \mathrm{kg} /$ day for 12 consecutive days. 
Group 5 (Sco+Pio $20 \mathrm{mg} / \mathrm{kg}$ group): A group that received scopolamine at a dose of $3 \mathrm{mg} / \mathrm{kg} / \mathrm{day}$ for one day and was treated with pioglitazone $20 \mathrm{mg} / \mathrm{kg} /$ day for 12 consecutive days.

All injections were intraperitoneal and pioglitazone was dissolved in DMSO.

48 hours after the last drug injection and after sacrificed rats, the hippocampus was rapidly isolated from rat brain tissue and used to study gene expression by real-time polymerase chain reaction. (RT-PCR) method.

\section{RNA extraction and RT-PCR}

The mRNA expression of IL-17A, TLR2, iNOS2, and arginase 1 were specified with the RT-PCR method. Total RNA was extracted from hippocampus tissue with the use of the Pars Tous RNA isolation Kit (Mashhad, Iran) according to the manufacturer's protocols. Their concentration was measured using NanoDrop. cDNA was synthesized using the cDNA synthesis kit (Pars Tous, Mashhad, Iran) following the manufacturer's protocols. The following specific primers were used: GAPDH Forward:

TGCCACTCAGAAGACTGTGG and GAPDH Reverse: TTCAGCTCTGGGATGACCTTG; Arginase-1 Forward: AAGAAAAGGCCGATTCAC and arginase 1 Reverse: CACCTCCTCTGCTGTCTTC; iNos2 Forward: ACCACCCTCCTCGTTCAG and iNOS2 Reverse: CAATCCACAACTCGCTCCA; TLR2 Forward: CGCTTCCTGAATTTGTCC and TLR2 Reverse: GTTGTCGCCTGCTTCCA; IL-17A Forward: CTACCTCAACCGTTCCAC and IL-17A Reverse: TCTCAGGCTCCCTCTTCAG. Finally, the $2^{-\triangle A C T}$ method was used as a relative quantification method to characterize the mRNA level of each gene [38].

\section{Statistical analysis}

Data were reported as the mean \pm SD. Data were statistically analyzed by ANOVA using the SPSS software version 16.0 (Armonk, USA). Differences among means of multiple groups were compared with Tukey's test, and $P<0.05$ was statistically significant.

\section{Results}

\section{Effect of pioglitazone on the mRNA expression of IL-17A}

Administration of scopolamine to rats increased significantly the mRNA expression of IL-17A in the Sco+DMSO group compared with the control group (Fig. 1, P< 0.05$)$. Injection of pioglitazone $(5,10$, and $20 \mathrm{mg} / \mathrm{kg}$ ) to rats decreased significantly the mRNA expression of IL-17A compared with the Sco+DMSO group (Fig. 1, P< 0.05). Effective dose was $20 \mathrm{mg} / \mathrm{kg}$ pioglitazone.

\section{Effect of pioglitazone on the mRNA expression of TLR2}


mRNA expression of TLR2 increased significantly in the Sco+DMSO group compared with a control group (Fig. 2, P< 0.05). Treatment of rats with different doses of pioglitazone $(5,10$, and $20 \mathrm{mg} / \mathrm{kg})$ decreased mRNA expression of TLR2 (Fig. 2). But this reduction was not significant compared with the Sco+DMSO group (Fig. 2) and also this reduction in mRNA expression of TLR2 was significant compared with the control group (Fig. 2, $\mathrm{P}<0.05$ ).

\section{Effect of pioglitazone on the mRNA expression of iNOS2}

Scopolamine administration could increase the mRNA expression of iNOS2 in the Sco+DMSO group compared with the control group (Fig. 3, P < 0.05). Pioglitazone could decrease the mRNA expression of iNOS2 compared with the Sco+DMSO group (Fig. 3, $\mathrm{P}<0.05$ ). Also, this reduction in the mRNA expression of iNOS2 was significant compared with a control group (Fig. $3, \mathrm{P}<0.05$ ).

\section{Effect of pioglitazone on the mRNA expression of arginase 1}

The mRNA expression of arginase 1 reduced significantly with scopolamine injection in Sco+DMSO group compared with control group (Fig. 4, $\mathrm{P}<0.05)$. Pioglitazone Injection $(5,10$ and $20 \mathrm{mg} / \mathrm{kg})$ to rats increased significantly the mRNA expression of arginase 1 compared with Sco+DMSO group (Fig. 4, P< 0.05). Effective dose was $20 \mathrm{mg} / \mathrm{kg}$ pioglitazone.

\section{Discussion}

Our results demonstrated that the treatment of pioglitazone, which is one of the PPARy agonists, led to a decrease in the mRNA expression of IL-17A, TLR2, and iNOS2 and an increase in the mRNA expression of arginase 1 in the rat hippocampus.

Important factors for induction/stimulation of AD are pro-inflammatory cytokines [39] such as IL17A [40]. IL-17A, a signature cytokine of T helper 17 cells, is involved in inflammation [41] and may have an important role in AD pathogenesis [41, 42]. Behairi et al. (2015) and Hamdan et al. (2014) showed baseline levels of IL-17A and the serum level IL-17A were significantly higher in AD patients compared with controls [40, 42, 43]. Also, Liu et al, (2021) [44] reported an increase in IL-17 in the hippocampus of APP/PS1 transgenic mice, and IL-17 induced an increase of A levels in mice. We also found that mRNA expression IL-17A increased in the hippocampus of scopolamine-treated rats.

Intrahippocampal injection of $A \beta 42$ into rats increased the expression of IL-17A in the hippocampus and also increased the cerebrospinal fluid and the serum of IL-17A in AD occurrence and development [45]. One of the plasma biomarkers for diagnosis of $A D$ and neocortical $A \beta$ load is the plasma IL-17A levels $[46,47]$. These findings suggest that blockage of IL-17 may reduce A $\beta$-induced neurotoxicity and cognitive impairment in $A D$ [44]. 
Nishimori et al. found that in response to bacterial entry into the intestinal mucosa, they produced IL-17A by direct TLR2 activation [48]. It is reported that energy deprivation up-regulated TLR2 in neurons and this may play a role in the AD pathogenesis [49]. TLR signaling have both beneficial and deleterious in AD and TLR2 expression can increase in the temporal cortex in AD [50,51]. Also, TLR2 up-regulated markedly compared to the control in a transgenic mouse model of AD [52]. It is reported that TLR2 deficiency decreased $A \beta$ deposition and neuroinflammation in a mouse model of AD [53]. Also, TLR2 deficiency decreased $A \beta$-induced inflammation, increased $A \beta$ clearance [54] in cultured microglia, and ameliorated tauopathies in mice, which shows useful effects of $\operatorname{TLR} 2$ in $\operatorname{AD}[55,56]$. Additionally, we found that mRNA expression TLR2 increased in the hippocampus of AD model rats.

iNOS expression can upregulate with IL17A, which is a proinflammatory cytokine [57]. iNOS appears to be a major initiator of $A B$ deposition and $A D$ progression, thus a treatment option for $A D$ may be inhibition of iNOS [58]. It is reported that intracerebroventricular $A \beta 1-40$ injection increase iNOS expression. The iNOS inhibition or the iNOS genetic deletion significantly ameliorates A $\beta 1-40$-induced impairment of learning and memory. The expression of iNOS has been strongly linked with AD pathology [59]. As we showed in this study, injection of scopolamine into rats to model AD increased the mRNA expression iNOS in the rat hippocampus.

In humans, arginase 1 is a cytosolic enzyme expressed in various areas of the brain especially in hippocampal neurons [19]. Arginase 1 is a marker of inflammation and stable arginase 1 expression reduces tau pathology and inflammatory response [60]. This enzyme has an important role in AD pathogenesis [19] so Kan et al ., found that arginase 1 is extremely expressed in $A \beta$ deposition areas [61]. It is reported that arginase 1 insufficiency in lysozyme $M$ increased $A \beta$ deposition, activated microglia, and behavioral impairments [21]. In this research we showed that scopolamine could decrease the mRNA expression arginase 1 in the rat hippocampus.

Inflammatory responses can modulate with PPARY agonists in the brain [18]. The PPARy agonist such as pioglitazone is FDA approved drug for diabetes treatment and has been used for treatment aims in animal models of central nervous system damage [62]. It is reported that the administration of pioglitazone improved inflammatory markers by reducing tumor necrotic factor a levels [63]. Also, it found that pioglitazone has an anti-inflammatory effect in the animal models of sub-acute and chronic inflammations [64]. As well as, regulating the PPARY/NF-KB pathway by pioglitazone nanoliposomes reduce the inflammatory response in sepsis-induced acute lung injury [65]. Also, pioglitazone administration reduces inflammation following traumatic brain injury [62]. Also, we found that in this study, pioglitazone can decrease inflammation in rat hippocampus after scopolamine injection.

One of the ways in which pioglitazone $(1 \mu \mathrm{M})$ can induce an anti-inflammatory effect is by inhibiting the Pam3CSK4-induced TLR2 expression in human monocytes and db/db mice [31]. Also, we found that pioglitazone $(5,10$, and $20 \mathrm{mg} / \mathrm{kg})$ can decrease the mRNA expression of TLR2 in scopolamine-treated rats. 
Pioglitazone (20 mg/kg, p.o. daily for 14 days), can inhibit the iNOS expression in mice model of AD [66]. In another study, pioglitazone could inhibit iNOS production in lipopolysaccharide-stimulated microglial cells [67]. As we found in this study, treatment with pioglitazone at different doses $(5,10$, and $20 \mathrm{mg} / \mathrm{kg}$, for 12 days) decreased the mRNA expression iNOS in rat hippocampus. It is reported that pioglitazone could decrease iNOS expression and increase the arginase 1 expression $[68,69]$. An in vivo study showed that expression of arginase 1 can increase in aortic macrophages isolated from pioglitazone-nanoparticle-treated mice [70]. As well, we showed that treatment with pioglitazone increases the mRNA expression of arginase 1 in scopolamine-treated rats.

These studies further suggest a potential benefit of pioglitazone in managing neuroinflammation, with reduction of pre-inflammation genes expression and increase of anti-inflammation genes expression.

\section{Conclusion}

It can be concluded that Pioglitazone with decreases the gene expression of Toll-like receptor 2, interleukin $A$ and inducible nitric oxide synthase 2 and with increases the gene expression of arginase- 1 in the rat brain, can reduce the inflammation in the rat's brain. So, Pioglitazone is useful for the protection of the brain against inflammation.

\section{Abbreviations}

AD: Alzheimer's disease; $A \beta$ : amyloid $\beta$; IL-17: interleukin-17; iNOS: inducible nitric oxide synthase; TLR2: toll-like receptor 2; PPAR: peroxisome proliferator activated receptor; DMSO: Dimethyl sulfoxide; RT-PCR: real-time polymerase chain reaction.

\section{Declarations}

\section{Ethics approval}

This study was approved by the Ethics Committee of Golestan University of Medical Sciences, Gorgan, Iran (Ethics number: ir.goums.rec.1399.346).

\section{Consent for publication}

Not applicable.

\section{Availability of data and materials}

You can request data information via the email below:

mejahanshahi@yahoo.com 


\section{Competing interests}

The authors confirm that there are no competing interests to declare.

\section{Funding}

The work was financially supported by the Research and Technology Vice-chancellor of Golestan University of Medical Sciences, Gorgan, Iran (Grant No: 111801).

\section{Authors' contributions}

Parisa Rahimi Chari collected the study data and writing the manuscript. Mehrdad Jahanshahi participated in hypothesis formation, supervision of data analysis, and writing the manuscript. Ali Memarian and Leila Elyasi analyzed the data and participated in writing the manuscript; all authors participated in critical revision of the manuscript and approved the final version.

\section{Acknowledgments:}

This article corresponds to a part of the Master's thesis in Anatomical Sciences by Parisa Rahimi Chari at the Gorgan School of Medicine/ Neuroscience Research Center of the Golestan University of Medical Sciences, Gorgan, Iran. We extend our gratitude to the Neuroscience Research Center.

\section{References}

1. Md S, Alhakamy NA, Alfaleh MA, Afzal O, Altamimi AS, lqubal A and Shaik RA. Mechanisms Involved in Microglial-Interceded Alzheimer's Disease and Nanocarrier-Based Treatment Approaches. J Pers Med. 2021;11(11):1116.

2. Gaetani L, Bellomo G, Parnetti L, Blennow K, Zetterberg H and Di Filippo M. Neuroinflammation and Alzheimer's Disease: A Machine Learning Approach to CSF Proteomics. Cells. 2021;10(8):1930.

3. Brigas HC, Ribeiro M, Coelho JE, Gomes R, Gomez-Murcia V, Carvalho K, Faivre E, Costa-Pereira S, Darrigues $\mathrm{J}$ and de Almeida AA. IL-17 triggers the onset of cognitive and synaptic deficits in early stages of Alzheimer's disease. Cell Rep. 2021;36(9):109574.

4. Kummer MP and Heneka MT. PPARs in Alzheimer's disease. PPAR research. 2008;2008(2008):403896.

5. Kim CF and Moalem-Taylor G. Interleukin-17 contributes to neuroinflammation and neuropathic pain following peripheral nerve injury in mice. J Pain. 2011;12(3):370-383.

6. Kwon S, Iba M, Masliah E and Kim C. Targeting microglial and neuronal toll-like receptor 2 in synucleinopathies. Exp Neurobiol. 2019;28(5):547-553. 
7. Sierra A, Navascués J, Cuadros MA, Calvente R, Martín-Oliva D, Ferrer-Martín RM, Martín-Estebané M, Carrasco M-C and Marín-Teva JL. Expression of inducible nitric oxide synthase (iNOS) in microglia of the developing quail retina. PLoS One. 2014;9(8):e106048.

8. Xia Y, Zhang Z, Lin W, Yan J, Zhu Ca, Yin D, He S, Su Y, Xu N and Caldwell RW. Modulating microglia activation prevents maternal immune activation induced schizophrenia-relevant behavior phenotypes via arginase 1 in the dentate gyrus. Neuropsychopharmacology. 2020;45(11):1896-1908.

9. Heshmati-Fakhr N, Sotoodehnejadnematalahi F, Yousefi N, Sayyah M, Hosseini SM and Pourbadie HG. Triggering microglia through toll-like receptor 2 pathway induced interferon $\beta$ expression in cell and animal model of Alzheimer's disease. Neuroreport. 2018;29(17):1456-1462.

10. Yu J-T, Mou S-M, Wang L-Z, Mao C-X and Tan L. Toll-like receptor 2-196 to -174 del polymorphism influences the susceptibility of Han Chinese people to Alzheimer's disease. J Neuroinflammation. 2011;8:136.

11. Ravari A, Mirzaei T, Kennedy D and Arababadi MK. Chronoinflammaging in Alzheimer; A systematic review on the roles of toll like receptor 2. Life Sci. 2017;171:16-20.

12. Tahara K, Kim H-D, Jin J-J, Maxwell JA, Li L and Fukuchi K-i. Role of toll-like receptor signalling in A $\beta$ uptake and clearance. Brain. 2006;129(11):3006-3019.

13. Downer EJ. Toll-like receptor signaling in Alzheimer's Disease Progression. J Alzheimers Dis Parkinsonism S. 2012;10:2161-0460.

14. Moseley T, Haudenschild DR, Rose L and Reddi AH. Interleukin-17 family and IL-17 receptors. Cytokine Growth Factor Rev. 2003;14(2):155-174.

15. Liu Q, Xin W, He P, Turner D, Yin J, Gan Y, Shi F-D and Wu J. Interleukin-17 inhibits adult hippocampal neurogenesis. Sci Rep. 2014;4(1):1-8.

16. Milovanovic J, Arsenijevic A, Stojanovic B, Kanjevac T, Arsenijevic D, Radosavljevic G, Milovanovic M and Arsenijevic N. Interleukin-17 in chronic inflammatory neurological diseases. Front Immunol. 2020;11:947.

17. Zhang G, He J-L, Xie X-Y and Yu C. LPS-induced iNOS expression in N9 microglial cells is suppressed by geniposide via ERK, p38 and nuclear factor-KB signaling pathways. Int $\mathrm{J}$ Mol Med. 2012;30(3):561-568.

18. Heneka MT, Klockgether T and Feinstein DL. Peroxisome Proliferator-Activated Receptor-g Ligands Reduce Neuronal Inducible Nitric Oxide Synthase Expression and Cell Death In Vivo. J Neurosci. 2000;20(18):6862-6867.

19. Polis B, Srikanth KD, Elliott E, Gil-Henn H and Samson AO. L-Norvaline reverses cognitive decline and synaptic loss in a murine model of Alzheimer's disease. Neurotherapeutics. 2018;15(4):1036-1054.

20. Fouda AY, Eldahshan W, Narayanan SP, Caldwell RW and Caldwell RB. Arginase pathway in acute retina and brain injury: therapeutic opportunities and unexplored avenues. Front Pharmacol. 2020;11:277.

21. Ma C, Hunt JB, Kovalenko A, Liang H, Selenica M-LB, Orr MB, Zhang B, Gensel JC, Feola DJ and Gordon MN. Myeloid Arginase 1 Insufficiency Exacerbates Amyloid- $\beta$ Associated Neurodegenerative 
Pathways and Glial Signatures in a Mouse Model of Alzheimer's Disease: A Targeted Transcriptome Analysis. Front Immunol. 2021;12.

22. Cherry JD, Olschowka JA and O'Banion MK. Arginase 1+ microglia reduce A $\beta$ plaque deposition during IL-1 $\beta$-dependent neuroinflammation. J Neuroinflammation. 2015;12(1):1-13.

23. Rafati A, Yazdani H and Noorafshan A. Pioglitazone ameliorates neuron loss in the cortex after aluminum-treatment in rats. Neurol Res Int. 2015;2015.

24. Seok H, Lee M, Shin E, Yun MR, Lee Y-h, Moon JH, Kim E, Lee PH, Lee B-W and Kang ES. Low-dose pioglitazone can ameliorate learning and memory impairment in a mouse model of dementia by increasing LRP1 expression in the hippocampus. Sci Rep. 2019;9(1):1-10.

25. Deng Y, Jiang X, Deng X, Chen H, Xu J, Zhang Z, Liu G, Yong Z, Yuan C and Sun X. Pioglitazone ameliorates neuronal damage after traumatic brain injury via the PPARY/NF-KB/IL-6 signaling pathway. Genes Dis. 2020;7(2):253-265.

26. Kapadia R, Yi J-H and Vemuganti R. Mechanisms of anti-inflammatory and neuroprotective actions of PPAR-gamma agonists. Front Biosci. 2008;13:1813.

27. Moreno S, Farioli-Vecchioli S and Ceru M. Immunolocalization of peroxisome proliferator-activated receptors and retinoid $X$ receptors in the adult rat CNS. Neuroscience. 2004;123(1):131-145.

28. Landreth G. Therapeutic use of agonists of the nuclear receptor PPARy in Alzheimer's disease. Curr Alzheimer Res. 2007;4(2):159-164.

29. Prakash A and Kumar A. Role of nuclear receptor on regulation of BDNF and neuroinflammation in hippocampus of $\beta$-amyloid animal model of Alzheimer's disease. Neurotox Res. 2014;25(4):335-347.

30. Cippitelli A, Domi E, Ubaldi M, Douglas JC, Li HW, Demopulos G, Gaitanaris G, Roberto M, Drew PD and Kane CJ. Protection against alcohol-induced neuronal and cognitive damage by the PPARY receptor agonist pioglitazone. Brain Behav Immun. 2017;64:320-329.

31. Dasu MR, Park S, Devaraj S and Jialal I. Pioglitazone inhibits Toll-like receptor expression and activity in human monocytes and db/db mice. Endocrinol. 2009;150(8):3457-3464.

32. Koufany M, Chappard D, Netter P, Bastien C, Weryha G, Jouzeau JY and Moulin D. The Peroxisome Proliferator-Activated Receptor y Agonist Pioglitazone Preserves Bone Microarchitecture in Experimental Arthritis by Reducing the Interleukin-17-Dependent Osteoclastogenic Pathway. Arthritis Rheum. 2013;65(12):3084-3095.

33. Ahmad A, Ramasamy K, Jaafar SM, Majeed ABA and Mani V. Total isoflavones from soybean and tempeh reversed scopolamine-induced amnesia, improved cholinergic activities and reduced neuroinflammation in brain. Food Chem Toxicol. 2014;65:120-128.

34. Wong-Guerra M, Jiménez-Martin J, Pardo-Andreu GL, Fonseca-Fonseca LA, Souza DO, de Assis AM, Ramirez-Sanchez J, Del Valle RM-S and Nuñez-Figueredo Y. Mitochondrial involvement in memory impairment induced by scopolamine in rats. Neurol Res. 2017;39(7):649-659.

35. Jang YJ, Kim J, Shim J, Kim C-Y, Jang J-H, Lee KW and Lee HJ. Decaffeinated coffee prevents scopolamine-induced memory impairment in rats. Behav Brain Res. 2013;245:113-119. 
36. Jahanshahi M, Nickmahzar E, Seif-Hoseini S, Babakordi F and Moharreri A. Scopolamine reduces the density of M1 muscarinic neurons in rats' hippocampus. Int J Morphol. 2013;31(4):1227-1232.

37. Jahanshahi M, Nikmahzar E and Gorgani S. Taurine can Decrease Phosphorylated Tau Protein Levels in Alzheimer's Model Rats' Brains. Kathmandu Univ Med J. 2021;74(2):200-204.

38. Mahakizadeh S, Jahanshahi M, Haidari K and Shahbazi M. Dopamine receptors gene expression in male rat hippocampus after administration of MDMA (Ecstasy)[La Expresión Génica de Receptores de Dopamina en el Hipocampo de Ratas Macho Después de la Administración de MDMA (Éxtasis)]. Int J Morphol. 2015;33(1):301-308.

39. Griffin WST. Neuroinflammatory cytokine signaling and Alzheimer's disease. N Engl J Med. 2013;368(8):770-771.

40. Chen J-M, Jiang G-X, Li Q-W, Zhou Z-M and Cheng Q. Increased serum levels of interleukin-18,-23 and-17 in chinese patients with Alzheimer's disease. Dement Geriatr Cogn Disord. 2014;38(5-6):321329.

41. Yang J, Kou J, Lalonde R and Fukuchi K-i. Intracranial IL-17A overexpression decreases cerebral amyloid angiopathy by upregulation of ABCA1 in an animal model of Alzheimer's disease. Brain Behav Immun. 2017;65:262-273.

42. Behairi N, Belkhelfa M, Mesbah-Amroun H, Rafa H, Belarbi S, Tazir M and Touil-Boukoffa C. All-transretinoic acid modulates nitric oxide and interleukin-17A production by peripheral blood mononuclear cells from patients with Alzheimer's disease. Neuroimmunomodulation. 2015;22(6):385-393.

43. Hamdan AA, Melconian AK, Adhia AH and Alhaidary AF. The level of IL-1a, IL-10 and IL-17A in Alzheimer's disease patients: comparative study. Baghdad Sci J. 2014;11:1486-1491.

44. Liu Y, Meng Y, Zhou C, Xia W, Wang L, Yan J, Cheng L, Dong W and Guo C. Blockage of IL-17 Ameliorates Aß-Induced Neurotoxicity and Cognitive Decline. 2021.

45. Zhang J, Ke K-F, Liu Z, Qiu Y-H and Peng Y-P. Th17 cell-mediated neuroinflammation is involved in neurodegeneration of aß1-42-induced Alzheimer's disease model rats. PloS one. 2013;8(10):e75786.

46. Samantha C SC, Faux N, Wilson W, Laws SM, Ames D, Bedo J, Bush Al, Doecke JD, Ellis KA and Head R. A blood-based predictor for neocortical $A \beta$ burden in Alzheimer's disease: results from the AIBL study. Mol Psychiatry. 2013;19(4):519-526.

47. Doecke JD, Laws SM, Faux NG, Wilson W, Burnham SC, Lam C-P, Mondal A, Bedo J, Bush Al and Brown B. Blood-based protein biomarkers for diagnosis of Alzheimer disease. Arch Neurol. 2012;69(10):1318-1325.

48. Nishimori JH, Newman TN, Oppong GO, Rapsinski GJ, Yen J-H, Biesecker SG, Wilson RP, Butler BP, Winter MG and Tsolis RM. Microbial amyloids induce interleukin 17A (IL-17A) and IL-22 responses via Toll-like receptor 2 activation in the intestinal mucosa. Infect Immun. 2012;80(12):4398-4408.

49. Tang S-C, Arumugam TV, Xu X, Cheng A, Mughal MR, Jo DG, Lathia JD, Siler DA, Chigurupati S and Ouyang $X$. Pivotal role for neuronal Toll-like receptors in ischemic brain injury and functional deficits. Proc Natl Acad Sci. 2007;104(34):13798-13803. 
50. Letiembre M, Liu Y, Walter S, Hao W, Pfander T, Wrede A, Schulz-Schaeffer W and Fassbender K. Screening of innate immune receptors in neurodegenerative diseases: a similar pattern. Neurobiol Aging. 2009;30(5):759-768.

51. Chakrabarty P, Li A, Ladd TB, Strickland MR, Koller EJ, Burgess JD, Funk CC, Cruz PE, Allen M and Yaroshenko M. TLR5 decoy receptor as a novel anti-amyloid therapeutic for Alzheimer's disease. J Exp Med. 2018;215(9):2247-2264.

52. Frank S, Copanaki E, Burbach GJ, Müller UC and Deller T. Differential regulation of toll-like receptor mRNAs in amyloid plaque-associated brain tissue of aged APP23 transgenic mice. Neurosci Lett. 2009;453(1):41-44.

53. Richard KL, Filali M, Préfontaine $P$ and Rivest $S$. Toll-like receptor 2 acts as a natural innate immune receptor to clear amyloid $\beta 1-42$ and delay the cognitive decline in a mouse model of Alzheimer's disease. J Neurosci. 2008;28(22):5784-5793.

54. Jana M, Palencia CA and Pahan K. Fibrillar amyloid- $\beta$ peptides activate microglia via TLR2: implications for Alzheimer's disease. J Immunol. 2008;181(10):7254-7262.

55. Rangasamy SB, Jana M, Roy A, Corbett GT, Kundu M, Chandra S, Mondal S, Dasarathi S, Mufson EJ and Mishra RK. Selective disruption of TLR2-MyD88 interaction inhibits inflammation and attenuates Alzheimer's pathology. J Clin Invest. 2018;128(10):4297-4312.

56. Pascual M, Calvo-Rodriguez M, Núñez L, Villalobos C, Ureña J and Guerri C. Toll-like receptors in neuroinflammation, neurodegeneration and alcohol-induced brain damage. IUBMB life. 2021.

57. Trajkovic V, Stosic-Grujicic S, Samardzic T, Markovic M, Miljkovic D, Ramic Z and Stojkovic MM. Interleukin-17 stimulates inducible nitric oxide synthase activation in rodent astrocytes. J Neuroimmunol. 2001;119(2):183-191.

58. Nathan C, Calingasan N, Nezezon J, Ding A, Lucia MS, La Perle K, Fuortes M, Lin M, Ehrt S and Kwon NS. Protection from Alzheimer's-like disease in the mouse by genetic ablation of inducible nitric oxide synthase. J Exp Med. 2005;202(9):1163-1169.

59. Medeiros R, Prediger RD, Passos GF, Pandolfo P, Duarte FS, Franco JL, Dafre AL, Di Giunta G, Figueiredo CP and Takahashi RN. Connecting TNF-a signaling pathways to iNOS expression in a mouse model of Alzheimer's disease: relevance for the behavioral and synaptic deficits induced by amyloid $\beta$ protein. J Neurosci. 2007;27(20):5394-5404.

60. Hunt JB, Nash KR, Placides D, Moran P, Selenica M-LB, Abuqalbeen F, Ratnasamy K, Slouha N, Rodriguez-Ospina S and Savlia M. Sustained arginase 1 expression modulates pathological tau deposits in a mouse model of tauopathy. J Neurosci. 2015;35(44):14842-14860.

61. Kan MJ, Lee JE, Wilson JG, Everhart AL, Brown CM, Hoofnagle AN, Jansen M, Vitek MP, Gunn MD and Colton CA. Arginine deprivation and immune suppression in a mouse model of Alzheimer's disease. J Neurosci. 2015;35(15):5969-5982.

62. Sauerbeck A, Gao J, Readnower R, Liu M, Pauly JR, Bing G and Sullivan PG. Pioglitazone attenuates mitochondrial dysfunction, cognitive impairment, cortical tissue loss, and inflammation following traumatic brain injury. Exp Neurol. 2011;227(1):128-135. 
63. Al-Muzafar $\mathrm{H}$, Alshehri $\mathrm{F}$ and Amin $\mathrm{K}$. The role of pioglitazone in antioxidant, anti-inflammatory, and insulin sensitivity in a high fat-carbohydrate diet-induced rat model of insulin resistance. Braz $\mathrm{J}$ Med Biol Res. 2021;54.

64. Sulaiman AA, Hussain SA, Jum'ma KM and Sigar AH. Evaluation of the anti-inflammatory effect of Pioglitazone in experimental models of inflammation in rats. Iraqi J Pharm Sci. 2009;30:18.

65. Yang C, Yin X, Cui Y, Xu D, Wang Z, Zhou Z, Tang J and Wu C. Pioglitazone nanoliposomes play an anti-inflammatory role in sepsis-associated lung injury by regulating the PPARY/NF-kB pathway. Mater Express. 2021;11(3):296-302.

66. Kaur B, Singh N and Jaggi AS. Exploring mechanism of pioglitazone-induced memory restorative effect in experimental dementia. Fundam Clin Pharmacol. 2009;23(5):557-566.

67. Ji H, Wang H, Zhang F, Li X, Xiang L and Aiguo S. PPARY agonist pioglitazone inhibits microglia inflammation by blocking p38 mitogen-activated protein kinase signaling pathways. Inflamm Res. 2010;59(11):921-929.

68. Chen Z, Yuan P, Sun X, Tang K, Liu H, Han S, Ye T, Liu X, Yang X and Zeng J. Pioglitazone decreased renal calcium oxalate crystal formation by suppressing M1 macrophage polarization via the PPAR-YmiR-23 axis. Am J Physiol Renal Physiol. 2019;317(1):F137-F151.

69. Jin X, Liu L, Zhou Ze, Ge J, Yao T and Shen C. Pioglitazone alleviates inflammation in diabetic mice fed a high-fat diet via inhibiting advanced glycation end-product-induced classical macrophage activation. The FEBS Journal. 2016;283(12):2295-2308.

70. Nakashiro S, Matoba T, Umezu R, Koga J-i, Tokutome M, Katsuki S, Nakano K, Sunagawa K and Egashira K. Pioglitazone-incorporated nanoparticles prevent plaque destabilization and rupture by regulating monocyte/macrophage differentiation in ApoE-/- mice. Arterioscler Thromb Vasc Biol. 2016;36(3):491-500.

\section{Figures}




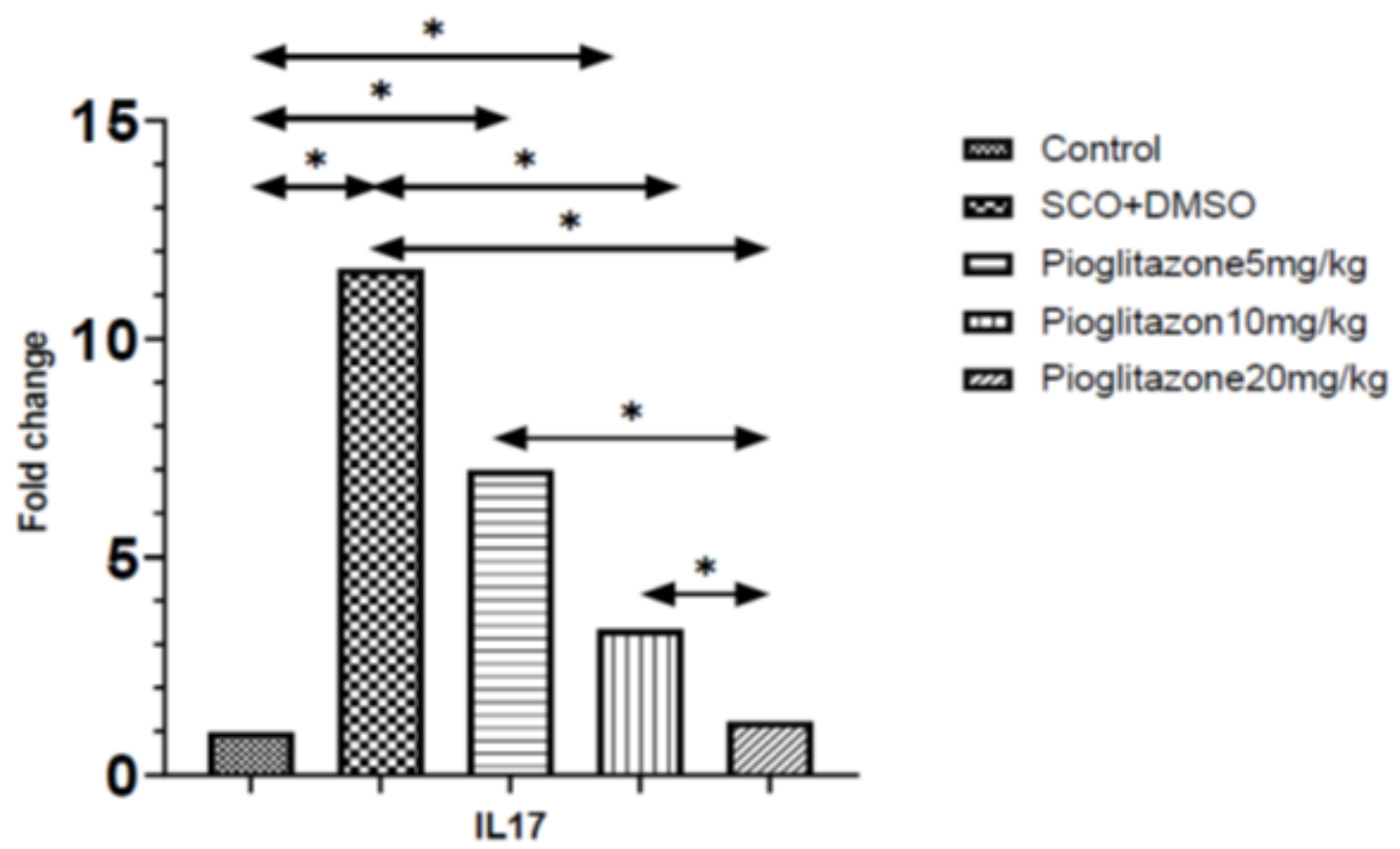

Figure 1

Effect of different doses of pioglitazone $(5,10$ and $20 \mathrm{mg} / \mathrm{kg}$ ) on the mRNA expression of IL-17A in rat hippocampus. * means $\mathrm{P}<0.05$.

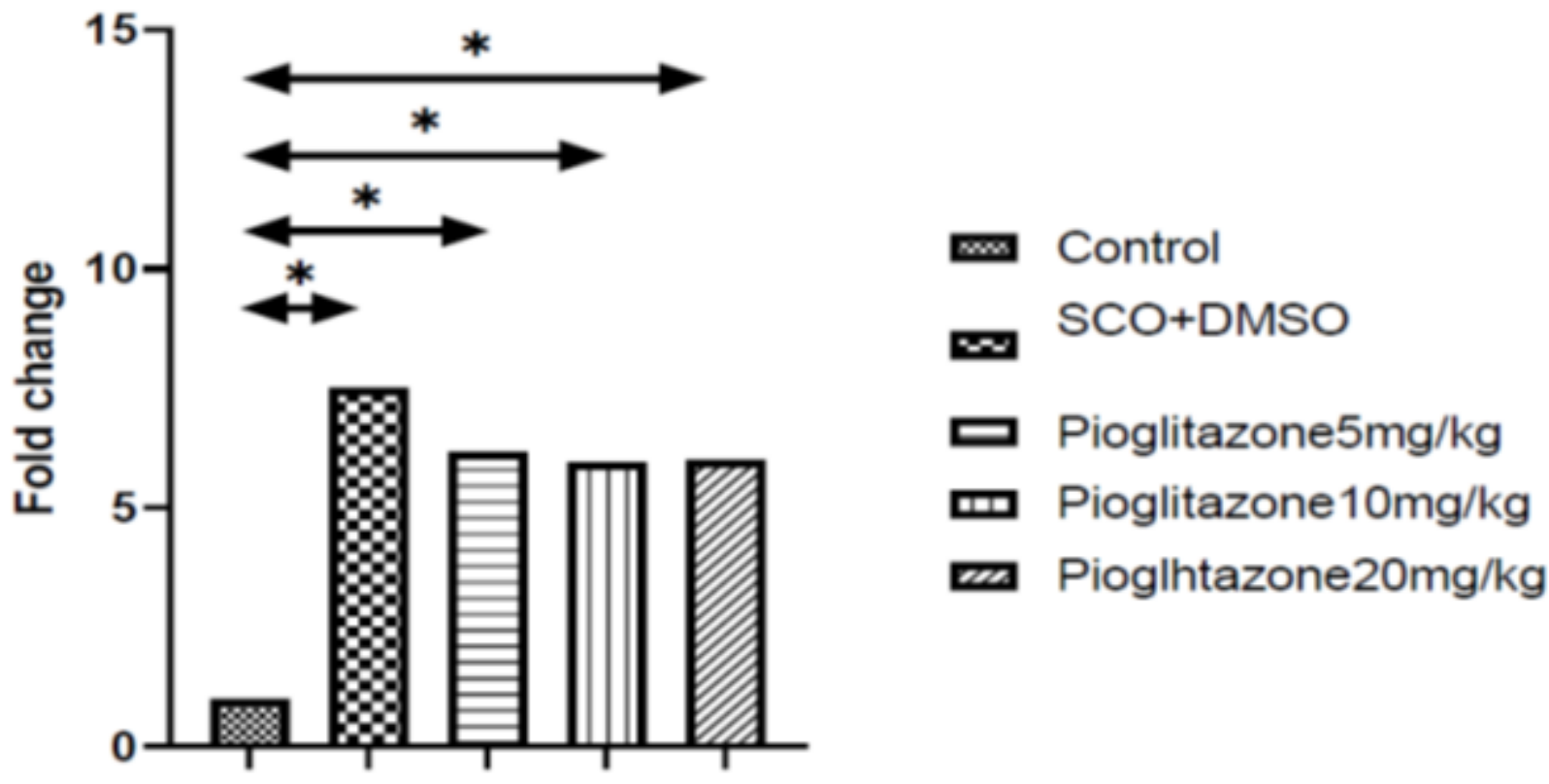

Figure 2 
Effect of different doses of pioglitazone $(5,10$ and $20 \mathrm{mg} / \mathrm{kg})$ on the mRNA expression of TLR2 in rat hippocampus. * means $\mathrm{P}<0.05$.

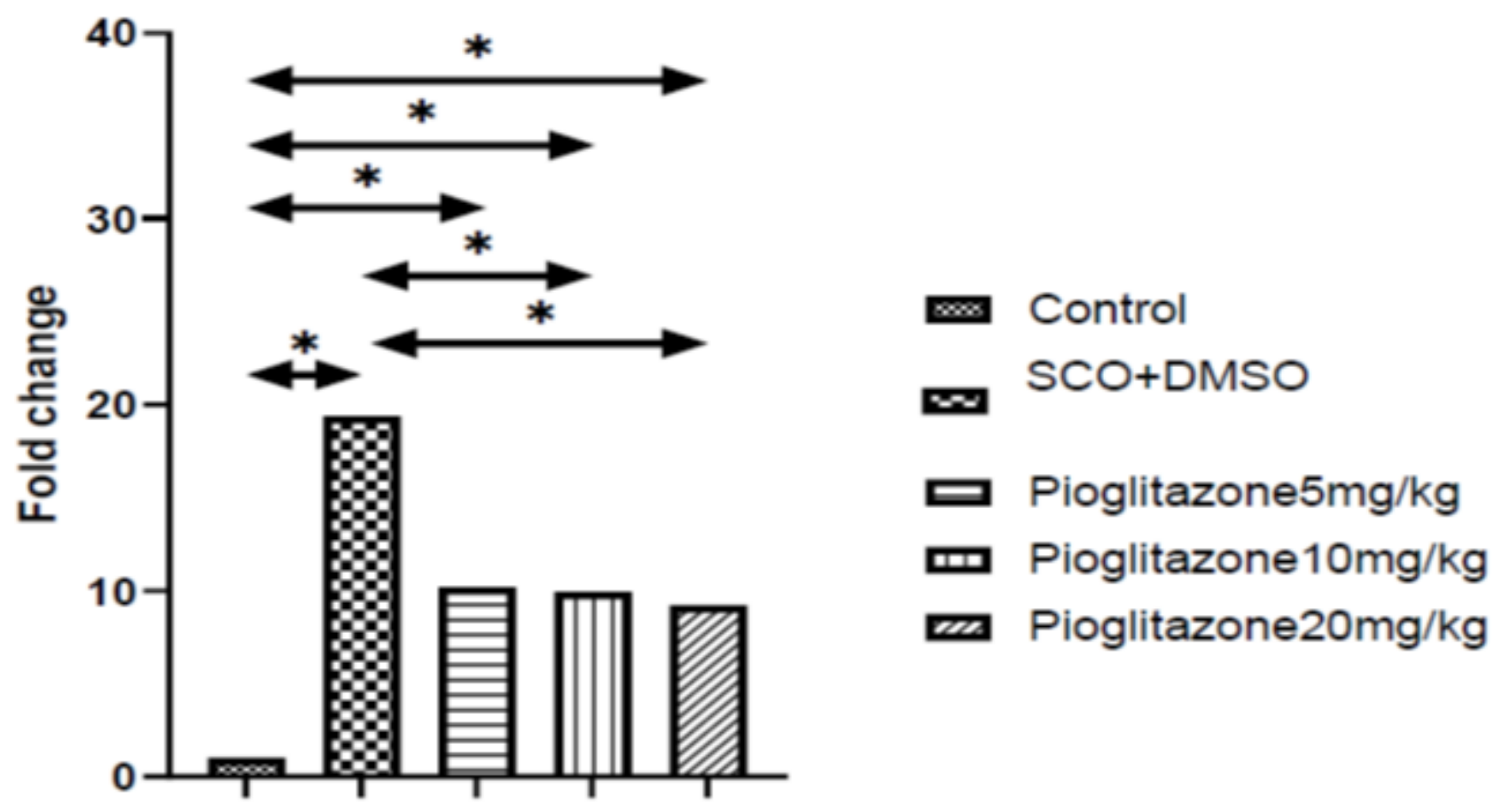

Figure 3

Effect of different doses of pioglitazone $(5,10$ and $20 \mathrm{mg} / \mathrm{kg}$ ) on the mRNA expression of iNOS2 in rat hippocampus. * means $\mathrm{P}<0.05$. 


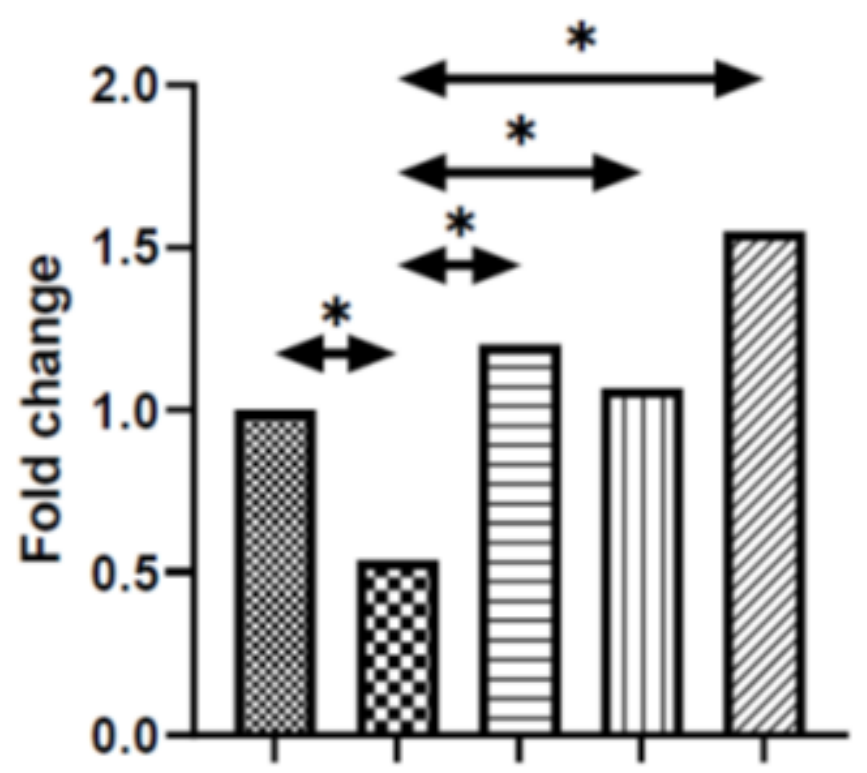

Control

Sco+DMSO

— Pioglitazone $5 \mathrm{mg} / \mathrm{kg}$

س. Pioglitazone10mg/kg

mioglitazone20mg/kg

Figure 4

Effect of different doses of pioglitazone $(5,10$ and $20 \mathrm{mg} / \mathrm{kg})$ on the mRNA expression of arginase 1 in rat hippocampus. * means $\mathrm{P}<0.05$. 